\title{
Structural insights into the catalytic mechanism of aldehyde-deformylating oxygenases
}

\author{
Chenjun $\mathrm{Jia}^{1,3}$, Mei $\mathrm{Li}^{1 \bowtie}$, Jianjun $\mathrm{Li}^{2}$, Jingjing Zhang ${ }^{2,3}$, Hongmei Zhang ${ }^{1}$, Peng Cao ${ }^{1}$, Xiaowei Pan ${ }^{1}$, \\ Xuefeng Lu ${ }^{2 \bowtie}$, Wenrui Chang ${ }^{1 \bowtie}$ \\ ${ }^{1}$ National Laboratory of Biomacromolecules, Institute of Biophysics, Chinese Academy of Sciences, Beijing 100101, China \\ ${ }^{2}$ Key Laboratory of Biofuels, Shandong Provincial Key Laboratory of Energy Genetics, Qingdao Institute of Bioenergy and \\ Bioprocess Technology, Chinese Academy of Sciences, Qingdao 266101, China \\ ${ }^{3}$ University of Chinese Academy of Sciences, Beijing 100049, China \\ $\triangle$ Correspondence: meili@moon.ibp.ac.cn (M. Li), Ivxf@qibebt.ac.cn (X. Lu), wrchang@sun5.ibp.ac.cn (W. Chang) \\ Received September 27, 2014 Accepted October 8, 2014
}

\begin{abstract}
The fatty alk(a/e)ne biosynthesis pathway found in cyanobacteria gained tremendous attention in recent years as a promising alternative approach for biofuel production. Cyanobacterial aldehyde-deformylating oxygenase (CADO), which catalyzes the conversion of $C_{n}$ fatty aldehyde to its corresponding $C_{n-1}$ alk(a/e)ne, is a key enzyme in that pathway. Due to its low activity, alk(a/e)ne production by cADO is an inefficient process. Previous biochemical and structural investigations of CADO have provided some information on its catalytic reaction. However, the details of its catalytic processes remain unclear. Here we report five crystal structures of cADO from the Synechococcus elongates strain PCC7942 in both its iron-free and iron-bound forms, representing different states during its catalytic process. Structural comparisons and functional enzyme assays indicate that Glu144, one of the iron-coordinating residues, plays a vital role in the catalytic reaction of CADO. Moreover, the helix where Glu144 resides exhibits two distinct conformations that correlates with the different binding states of the di-iron center in CADO structures. Therefore, our results provide a structural explanation for the highly labile feature of cADO di-iron center, which we proposed to be related to its low enzymatic activity. On the basis of our structural and biochemical data, a possible catalytic process of cADO was proposed, which could aid the design of cADO with improved activity.
\end{abstract}

KEYWORDS aldehyde-deformylating oxygenase, di-iron center, crystal structure, catalytic mechanism, alk(a/e)ne production

\section{INTRODUCTION}

Fatty alk(a/e)nes are major components of fuel oil and one of the ideal alternatives for fossil-based biofuels. Recently, Schirmer et al. identified two genes from cyanobacteria that encode an acyl-ACP reductase (AAR) and an aldehydedeformylating oxygenase (ADO), both of which are responsible for alkane production in cyanobacteria (Li et al., 2012; Schirmer et al., 2010). This pathway has drawn considerable attention, since this route provides a promising approach for photosynthetic production of alka(e)ne biofuels (Krebs et al., 2011; Wang et al., 2013). In this two-step pathway, AAR reduces fatty acyl-ACPs or -CoAs into their corresponding aldehydes, and subsequently the $C_{n}$ fatty aldehydes are converted into their corresponding $C_{n-1}$ alk $(a / e)$ nes by $A D O$ (Schirmer et al., 2010).

Cyanobacterial aldehyde-deformylating oxygenase (cADO) belongs to the superfamily of ferritin-like di-iron proteins (Krebs et al., 2011) and contains a di-iron center (Das et al., 2011). However, metal analysis indicated that less than one fifth of the purified protein in a typical preparation contains iron (Das et al., 2011), assuming two iron atoms per enzyme molecule, the results indicated that the iron atoms may be loosely bound to CADO. The in vitro reaction catalyzed by CADO requires both the dioxygen as co-substrate and the presence of a reducing system, which 
provides four electrons per turnover (Warui et al., 2011) and can either be biological (ferredoxin, ferredoxin reductase, and NADPH; Fd/FR/N) (Schirmer et al., 2010; Warui et al., 2011) or chemical (phenazine methosulfate and NADH; P/N) (Das et al., 2011). It was proposed that the incorporation of $\mathrm{O}_{2}$ into the reduced cofactor generates an iron-peroxo species that attacks the substrate aldehyde to form a hemiacetal and followed by the scission of its $\mathrm{C}_{1}-\mathrm{C}_{2}$ bond ( $\mathrm{Li}$ et al., 2012; Li et al., 2011). The ensuing product of the reaction is a $\mathrm{C}_{\mathrm{n}-1}$ alkane ( $\mathrm{Li}$ et al., 2011), and the $\mathrm{C}_{1}$-derived co-product was demonstrated to be formate (Warui et al., 2011). Isotope-tracer assay revealed that the oxygen atom in the product formate originates from the co-substrate $\mathrm{O}_{2}$ ( $\mathrm{Li}$ et al., 2012). Recent reports suggested that cADO also catalyzes the incorporation of an oxygen atom from $\mathrm{O}_{2}$ into its alkane product for $\mathrm{C}_{9-10}$ aldehyde substrates, which yields both $\mathrm{C}_{n-1}$ alcohol and aldehyde products, implying a function for CADO in oxygenation, in addition to deformylation (Aukema et al., 2013; Das et al., 2014). An intriguing feature of cADO is its low in vitro activity (Das et al., 2011; Eser et al., 2012; Li et al., 2011), with only 3-5 turnovers (Andre et al., 2013; Warui et al., 2011). Andre et al. reported that cADO is reversibly inhibited by the side product $\mathrm{H}_{2} \mathrm{O}_{2}$, and its inhibition can be relieved by adding catalase in enzyme assays (Andre et al., 2013). Subsequently, it was demonstrated that the output of $\mathrm{H}_{2} \mathrm{O}_{2}$ can be reduced by over $30 \%$ in the presence of a cognate biological reducing system Fd/FR/N (Zhang et al., 2013). In addition, when cADO was fused with cognate FR and Fd in a specific order, it displayed a 3-fold increase in activity relative to native cADO (Wang et al., 2014).

Crystal structures of ADO from cyanobacterium Prochlorococcus marinus (Pm) MIT9313 (wild-type and two singlepoint mutants) were reported (Khara et al., 2013). Structures showed that PmADO adopted an a-helical folding, with two iron atoms coordinated by histidines and carboxylate ligands (Khara et al., 2013; Schirmer et al., 2010). A long-chain ligand, which was subsequently identified as a mixture of fatty acid molecules (Khara et al., 2013), was observed in the vicinity of the di-iron center in these structures (Khara et al., 2013). This pocket accommodating fatty acid molecules were suggested to be the substrate channel. However, due to the structural difference between fatty acid and the real substrate fatty aldehyde, the interaction between ADO and the substrate remains elusive. In addition, their structural resemblance indicated that they may represent one similar state of the reaction process, thus structures of cADO at different dynamic stages during its reaction cycle will be of great help for understanding its detailed catalytic process.

To gain insights into the reaction catalyzed by CADO, we determined structures of wild type ADO from Synechococcus elongates PCC7942 ( $\mathrm{Se}$ ) with different treatment (WT0, no treatment; WT1, co-crystallized with iron; WT-HP, soaked in $\mathrm{H}_{2} \mathrm{O}_{2}$ ), and solved the structures of two SeADO mutants (Y122F and F86YF87Y). Comparison of all our structures revealed that their overall conformations are closely
Figure 1. Sequence and structure of SeADO. (A) Sequence alignment of cADOs from different species. The secondary structure elements are indicated. The residues comprising the conserved iron-binding motifs are indicated with blue arrow and labelled. The conserved residues involved in substrate channel formation are indicated with yellow arrow. (B) Overall structure of SeADO (molecule A of WT1 structure), secondary structure was labelled, iron atoms are shown as spheres. (C) Structural comparison of iron-bound SeADO structures. The black square marked the $\mathrm{H} 5$ region (left panel). The 2Fo - Fc $(1.0 \sigma$ level) electron density of this segment in WT1 structure (H5) was shown in right panel. (D) Structural comparison of iron-free SeADO structures. The black square marked the $\mathrm{L} 5$ region (left panel). The $2 \mathrm{Fo}-\mathrm{Fc}$ $(1.0 \sigma$ level) electron density of this segment in WTO structure (L5) was shown in right panel. (E) Structural comparison of the iron-bound SeADO (molecule A of Y122F structure) and the iron-free SeADO (WTO structure). The right panel shows the different conformation of H5 and L5. Residues 144-150 are shown as stick and the two iron-coordinating residues Glu144 and His147 are indicated. The WT0, Y122F, WT1, F86YF87Y and WT-HP structures are shown in lime, yellow, cyan, orange and magenta, respectively in Fig. 1C-E.

resembling each other, while the conformation of their active sites are largely different. Analysis of all these structures indicated that they may represent different states of the enzyme in the reaction cycle. Except WT-HP structure, which is similar to that of the PmADO, the other four structures exhibit different conformations in their active sites that were not described previously.

\section{RESULTS AND DISCUSSION}

\section{Overall structure of SeADO}

SeADO belongs to the di-iron protein family, with conserved sequence of two $\mathrm{EX}_{28-29} \mathrm{EX}_{2} \mathrm{H}$ motifs (Kurtz, 1997; Merkx et al., 2001), in which six conservative amino acids from four helices (Glu32 from helix H1, Glu115 from helix H4, Glu60 \& His63 from helix H2, and Glu144 \& His147 from helix H5) act as metal ligands (Fig. 1A). Interestingly, we found that not every molecule in our five SeADO structures possess a fully occupied di-iron center, even though the protein was cocrystalized with $4 \mathrm{mmol} / \mathrm{L}$ ferrous ammonium sulfate. Each asymmetric unit of WTO crystal contains one SeADO molecule, and its active site appears to have lost both of its iron atoms. The other four structures all contain two molecules in an asymmetric unit, with at least one molecule containing a di-iron center (Table 1).

Either with or without di-iron cluster, the overall structures of all these molecules are similar, with the exception of one specific helix conformation. In the structures of $\mathrm{Y} 122 \mathrm{~F}$ and 

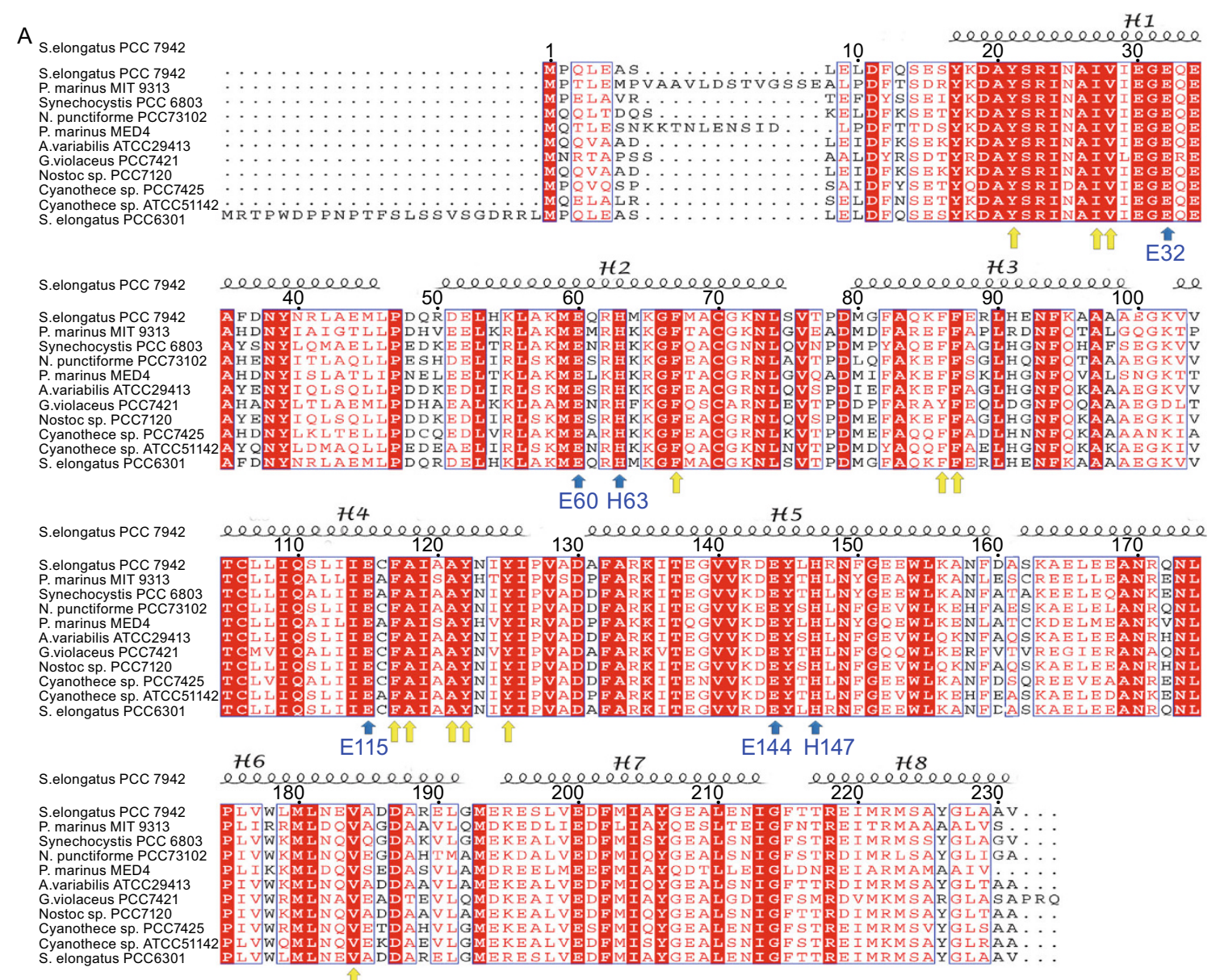

B
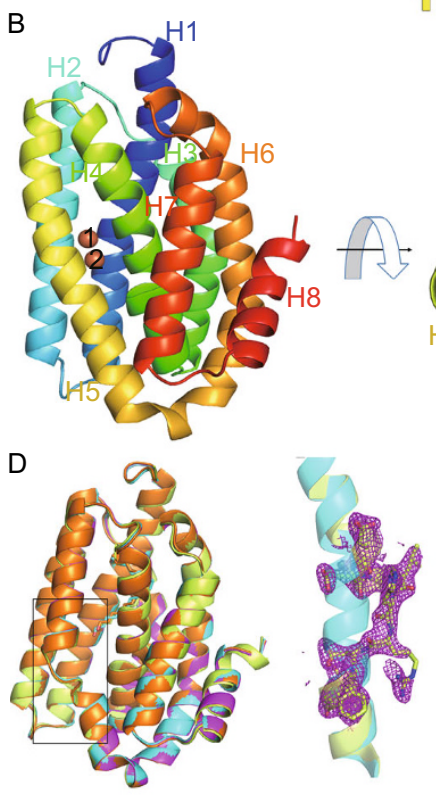
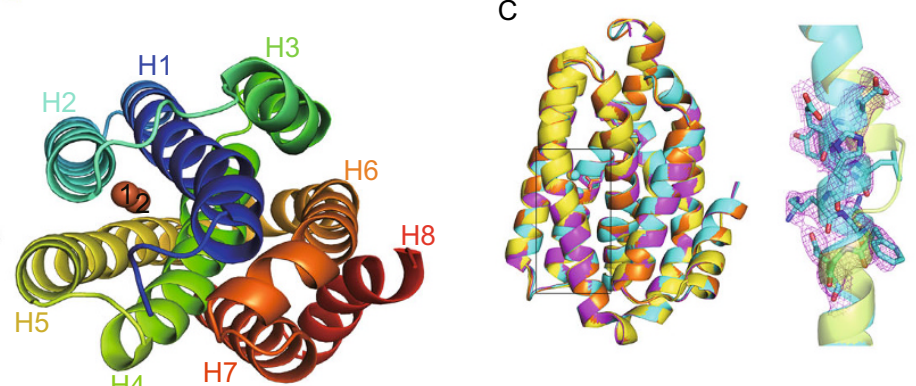

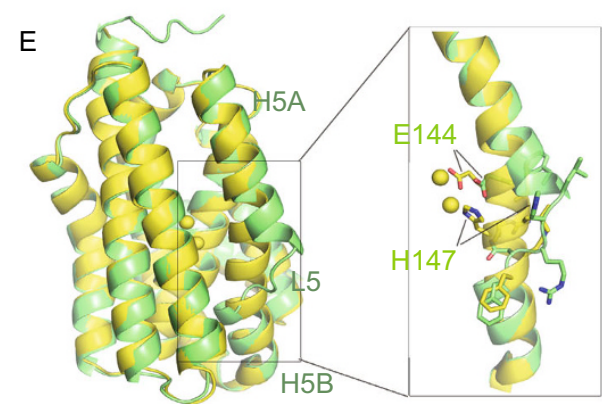

molecule A of other threes (WT1, F86YF87Y and WT-HP), the ADO molecule adopts an all-helical folding, comprising of eight $\alpha$-helices ( $\mathrm{H} 1-\mathrm{H} 8)$ that form a compact structure (Fig. 1A and $1 \mathrm{~B}$ ). Two iron atoms ( $\mathrm{Fe} 1$ and $\mathrm{Fe} 2$ ) are surrounded by a four-helix bundle, which is composed of $\mathrm{H} 1$ (S16-M45), H2 (R50-L74), H4 (V103-I126) and H5 (A131-D160). 
Table 1. Statistics of data processing, structure refinement and summary of different structures of SeADO

\begin{tabular}{|c|c|c|c|c|c|}
\hline PDB ID & $\begin{array}{l}\text { WTO } \\
\text { 4QUW }\end{array}$ & $\begin{array}{l}\mathrm{Y} 122 \mathrm{~F} \\
4 \mathrm{RC} 6\end{array}$ & $\begin{array}{l}\text { WT1 } \\
\text { 4RC5 }\end{array}$ & $\begin{array}{l}\text { F86YF87Y } \\
4 R C 7\end{array}$ & $\begin{array}{l}\text { WT-HP } \\
\text { 4RC8 }\end{array}$ \\
\hline \multicolumn{6}{|l|}{ Data collection } \\
\hline Space group & $\mathrm{P} 4{ }_{1} 2_{1} 2$ & $\mathrm{P} 2{ }_{1} 2_{1} 2_{1}$ & $\mathrm{P} 2{ }_{1} 2_{1} 2_{1}$ & $\mathrm{P} 2{ }_{1} 2_{1} 2_{1}$ & $\mathrm{P} 2{ }_{1} 2_{1} 2_{1}$ \\
\hline \multirow[t]{3}{*}{ Cell parameters $(\AA)$} & $a=61.7$ & $a=64.73$ & $a=61.7$ & $a=62.0$ & $a=61.7$ \\
\hline & $b=61.7$ & $b=64.71$ & $b=61.8$ & $b=62.1$ & $b=61.9$ \\
\hline & $c=110.5$ & $c=101.4$ & $c=124.9$ & $c=125.0$ & $c=124.8$ \\
\hline Resolution $(\AA)$ & $\begin{array}{l}50.0-2.26 \\
(2.30-2.26)\end{array}$ & $\begin{array}{l}50.0-2.9 \\
(2.95-2.9)\end{array}$ & $\begin{array}{l}50.0-2.3 \\
(2.34-2.3)\end{array}$ & $\begin{array}{l}50.0-2.2 \\
\quad(2.28-2.2)\end{array}$ & $\begin{array}{l}50.0-1.71 \\
\quad(1.74-1.71)\end{array}$ \\
\hline No. of unique refls & 19017 & 9504 & 21848 & 24713 & 50505 \\
\hline$R_{\text {merge }}$ (\%overall/outmost shell) & $3.9 / 36.9$ & $6.0 / 50.9$ & $13.0 / 49.0$ & $17.0 / 71.8$ & $7.3 / 48.3$ \\
\hline$/ / \sigma(I)$ (overall/outmost shell) & $38.8 / 4.8$ & $22.5 / 3.4$ & $15.1 / 4.0$ & $71.5 / 25.2$ & $34.7 / 7.9$ \\
\hline $\begin{array}{l}\text { Completeness } \\
\text { (\% overall/outmost shell) }\end{array}$ & $99.8 / 99.8$ & $84.9 / 99.3$ & $99.8 / 100.0$ & $98.5 / 99.1$ & $99.8 / 100$ \\
\hline \multicolumn{6}{|l|}{ Refinement } \\
\hline$R_{\text {factor }}(\%)$ & 20.4 & 25.6 & 20.9 & 20.4 & 18.9 \\
\hline$R_{\text {free }}(\%)$ & 24.6 & 29.5 & 24.2 & 24.1 & 21.2 \\
\hline \multicolumn{6}{|l|}{ RMS deviations } \\
\hline Bond lengths $(\AA)$ & 0.011 & 0.011 & 0.012 & 0.009 & 0.007 \\
\hline Bond angles $\left({ }^{\circ}\right)$ & 1.207 & 1.462 & 1.382 & 1.128 & 0.934 \\
\hline Mean $B$ value $\left(\AA^{2}\right)$ & 35.3 & 46.8 & 26.2 & 26.7 & 16.3 \\
\hline \multicolumn{6}{|l|}{ Structure summary } \\
\hline $\begin{array}{l}\text { Iron incorporation before } \\
\text { crystallization }\end{array}$ & No & Yes & Yes & Yes & Yes \\
\hline Treatment of crystals & - & - & - & - & $\mathrm{H}_{2} \mathrm{O}_{2}$ soaked \\
\hline No. of molecules in a.u. & 1 & 2 & 2 & 2 & 2 \\
\hline No. of di-iron center in a.u. & 0 & 2 & 1 & $1+0.5$ & 1 \\
\hline Location of di-iron center & - & $\begin{array}{l}\text { Molecules A } \\
\text { and B }\end{array}$ & Molecule A & $\begin{array}{l}\text { Molecules A } \\
\text { and B }\end{array}$ & Molecule A \\
\hline Ligand & $\begin{array}{l}\mathrm{L}_{\text {red }} \text { (Fatty } \\
\text { alcohol) }\end{array}$ & - & $\begin{array}{l}\mathrm{L}_{\text {red }} \text { (Fatty } \\
\text { alcohol) }\end{array}$ & $\begin{array}{l}\mathrm{L}_{\text {red }} \text { (Fatty } \\
\text { alcohol) }\end{array}$ & $\mathrm{L}_{\mathrm{ox}}$ (Fatty acid) \\
\hline Oxo-bridge & - & No & No & No & Yes \\
\hline Ligated water & - & No & No & Yes & Yes \\
\hline
\end{tabular}

Unlike other structural elements in SeADO, helix $\mathrm{H} 5$ is unique in representing two distinct conformations in different structures. In the structures mentioned above, $\mathrm{H} 5$ exists as a long helix (Fig. 1C), where two residues (Glu144 and $\mathrm{His} 147)$ in the second $\mathrm{EX}_{2} \mathrm{H}$ motif are coordinated or close to iron atoms. By contrast, the helix $\mathrm{H} 5$ is unwound in the middle in the structures of WTO and molecule B of other three structures (WT1, F86YF87Y and WT-HP), forming two short helices (H5A and $\mathrm{H} 5 \mathrm{~B})$ that are connected by a loop L5 (Fig. 1D and 1E). The helix to loop transition results in a different conformation for a number of amino acids (from residue 144 to 150), thus the two iron-coordinating residues (Glu144 and His147) move away from the di-iron site
(Fig. 1E). As a result, most of our SeADO structures with the L5 conformation lose their metal atoms. The only exception is molecule $B$ in the F86YF87Y structure, which contains the di-metal cluster while exhibiting the L5 conformation. However, the relatively weak electron density indicates a low occupancy of the two iron atoms in this molecule.

The fact of the partially bound iron atoms observed in our ADO structures is in agreement with previous iron content results for PmADO proteins (Das et al., 2011), as well as our ICP-OES analysis on SeADO protein samples. Our analysis showed that the content of iron in ADO is relatively low when no iron was added during protein 
Table 2. Iron content of wild type and mutants of SeADO measured by ICP-OES assay

\begin{tabular}{|c|c|c|c|c|c|}
\hline \multirow[t]{2}{*}{ Protein } & \multicolumn{3}{|c|}{ Expression conditions } & \multirow{2}{*}{$\begin{array}{l}\text { Number of iron atom } \\
\text { per ADO molecule }\end{array}$} & \multirow{2}{*}{$\begin{array}{l}\text { Percentage of iron content } \\
\text { compared with wild type } 3\end{array}$} \\
\hline & LB medium & TB medium & $\mathrm{LB}$ medium $+\mathrm{Fe}$ & & \\
\hline Wild type 1 & $\sqrt{ }$ & & & $0.28 \pm 0.004$ & $17.7 \% \pm 0.25 \%$ \\
\hline Wild type 2 & & $\sqrt{ }$ & & $0.67 \pm 0.02$ & $42.4 \% \pm 1.27 \%$ \\
\hline Wild type 3 & & & $\sqrt{ }$ & $1.58 \pm 0.09$ & $100 \% \pm 5.7 \%$ \\
\hline E144A & & & $\sqrt{ }$ & $1.58 \pm 0.06$ & $99.9 \% \pm 3.81 \%$ \\
\hline Y122F & & & $\sqrt{ }$ & $1.69 \pm 0.12$ & $107.38 \% \pm 7.7 \%$ \\
\hline F86YF87Y & & & $\sqrt{ }$ & $1.30 \pm 0.26$ & $82.29 \% \pm 16.78 \%$ \\
\hline A129insl & & & $\sqrt{ }$ & $1.60 \pm 0.29$ & $101.32 \% \pm 18.17 \%$ \\
\hline A129insIF & & & $\sqrt{ }$ & $1.58 \pm 0.03$ & $100.25 \% \pm 1.63 \%$ \\
\hline L146S & & & $\sqrt{ }$ & $1.48 \pm 0.01$ & $93.96 \% \pm 0.76 \%$ \\
\hline R148A & & & $\sqrt{ }$ & $1.53 \pm 0.08$ & $96.64 \% \pm 5.17 \%$ \\
\hline N149A & & & $\sqrt{ }$ & $1.35 \pm 0.23$ & $85.50 \% \pm 14.71 \%$ \\
\hline
\end{tabular}
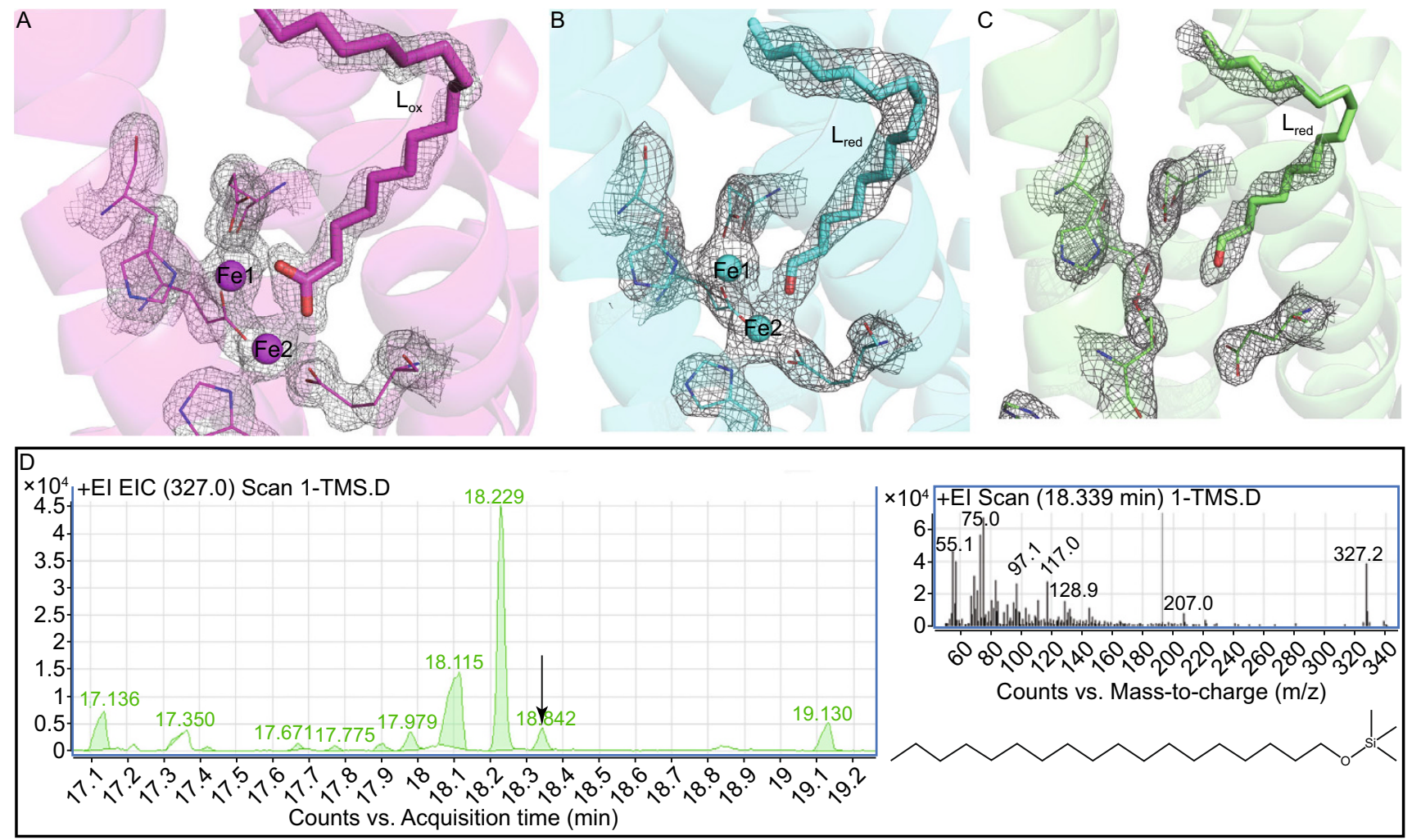

Figure 2. Analysis of the ligands bound in SeADO. (A-C) The $2 \mathrm{Fo}-\mathrm{Fc}(1.0 \sigma$ level) electron density of the ligand, iron atoms and the conserved iron-coordinating residues in WT-HP (A), WT1 (B), and WT0 (C) structures. Iron atoms are shown in spheres, the ligands are shown in sticks and the residues are shown in lines. The WT-HP, WT1, and WT0 structures are shown in magenta, cyan, and lime, respectively. (D) GC-QqQ-MS/MS analysis and verification of the unknown ligands. The sample after extraction was trimethylsilylated for analysis on GC-QqQ-MS/MS. 1-(Trimethylsilyloxy)octadecane (CAS No.18748-98-6), the derivative of 1-hydroxyoctadecane, was identified to the peak of acquisition time 18.34 min (indicated by the black arrow).

expression. Even after adding higher concentrations of iron to the culture medium, we were unable to obtain proteins with fully occupied di-iron centers (Table 2). Our results suggest that the lability of iron atoms at $A D O$ active site is possibly related to the flexible conformation of helix $\mathrm{H} 5$. 


\section{Substrate channel in SeADO}

In four of our five structures (except the Y122F structure), a continuous tube-shaped non-protein electron density, resembling a lipid molecule, was observed close to the diiron center (Fig. 2). A similar ligand was also found in earlier PmADO structures (Khara et al., 2013; Schirmer et al., 2010). Using GC-MS analysis, Khara, et al. identified the ligand to be a mixture of long-chain fatty acids, with two components of the ligand extracts yet awaiting identification (Khara et al., 2013). In our WT-HP structure, a long-chain fatty acid molecule with a bifurcated head-group configuration fits the electron density well (Fig. 2A). However, in the WT1 and WT0 structures, the electron density is consistent with a ligand with one single-head-group configuration, which is unlikely to be a fatty acid (Fig. $2 \mathrm{~B}$ and $2 \mathrm{C}$ ). The differing electron densities observed in F86YF87Y structure suggest the presence of a mixture of ligands with different head groups.

To identify the precise nature of these ligands, the ligands extracted from SeADO protein samples were analyzed by GC-QqQ-MS/MS. The results showed that the majority of the ligands examined were a mixture of long-chain fatty acids, and the dominant of the remaining components was identified as a C18 fatty alcohol (Fig. 2D). Following the analysis of the extracts together with the observed electron densities, we built a long-chain fatty acid $\left(\mathrm{L}_{\mathrm{ox}}\right)$ into the structure of WT$H P$, and a long-chain fatty alcohol $\left(L_{\text {red }}\right)$ into three other structures. On the basis of these observations, we propose that the $L_{\text {red }}$ ligand may represent the real substrate, namely fatty aldehyde, because of the similarity in their chemical structures.

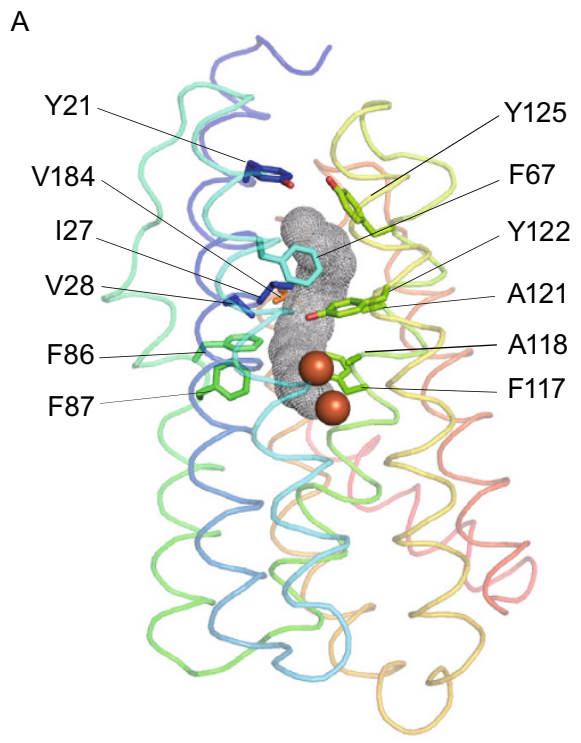

In our different structures, the ligand is buried inside ADO molecule at the same location, with its hydrophobic tail pointing towards the $\mathrm{N}$-terminal region. A number of aromatic and hydrophobic residues, which are highly conserved among diverse species of cADOs (Fig. 1A), form a hydrophobic channel to accommodate the non-polar ligand (Fig. 3A). Notably, whilst all these residues are provided by helices 1, 2, 3, 4 and 6, helix $\mathrm{H} 5$ is contributing little to the formation of the hydrophobic channel. This peculiar structural feature might explain why the ligands remain in the channel even in the absence of the di-iron cluster (Fig. 2C), despite the fact that the conformation of helix $\mathrm{H} 5$ is vastly different among our structures. We proposed that the hydrophobic channel is the actual substrate channel of cADO.

The analysis of our structures showed that the substrate channel is in an occluded mode. Many interactions exist between residues from several loops covering the entrance of the substrate channel in the shape of a lid (Fig. 3B). We constructed two mutants with one or two non-polar bulky residues (I or IF) inserted after A129 (A129insl and A129ins IF) to lengthen the loop between $\mathrm{H} 4$ and $\mathrm{H} 5$. The enzymatic assay showed that both mutants exhibited only up to half of the activity of that observed for wild type (Fig. 4). We propose that a longer loop may lead to the steric hindrance at the entrance of substrate channel, which could result in the reduction of ADO activity. In addition, two Tyr (Y125 and Y21) form a hydrogen bond at the entrance of the substrate channel, sealing the ligand inside the protein molecule (Fig. 3). The above-mentioned structural features might be one of the reasons that CADO appears inactive

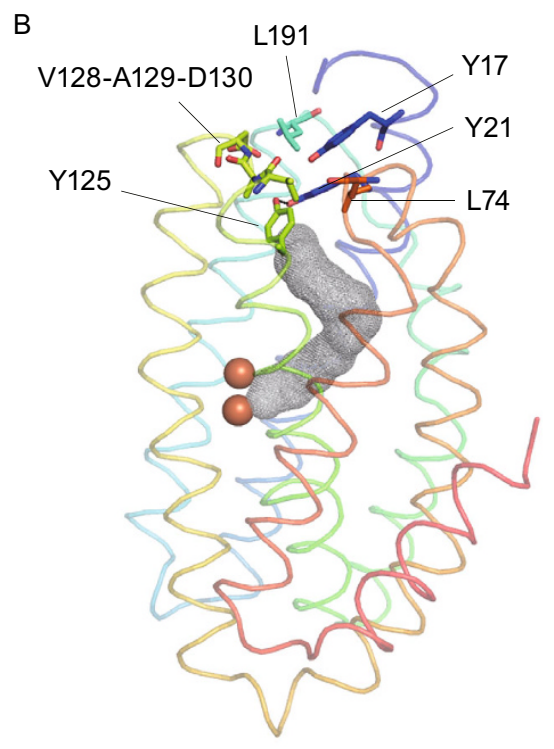

Figure 3. The substrate channel of SeADO. (A) The conserved residues involved in the formation of the substrate channel are labelled. (B) The substrate channel is sealed by the hydrogen bond (shown as black dashed line) formed by two Tyr residues (Y21 and $\mathrm{Y} 125$ ) and a shell-like cover comprises of V128-D130 together with Y17, L74, and L191. The iron atoms are shown in spheres, and the substrate channel is shown as grey mesh. 
when longer-chain aldehydes like C24 are used as substrate (Andre et al., 2013).

\section{SeADO structures that represent the different states during catalytic reaction}

In order to test the effects of residues surrounding the di-iron center and substrate channel on cADO's catalytic activity, we constructed several mutant forms by site-directed mutagenesis, and then determined the iron content and enzymatic activity of these mutants relative to the wild type (Fig. 4 and Table 2). In addition, the crystal structures of specific mutants were solved. Intriguingly, two mutant structures (Y122F and F86YF87Y) and three wild type structures exhibit different conformations at their active site (Fig. 5) which may represent different states of the enzyme in the reaction cycle. Based on the character of the ligand molecules and the coordination mode of the iron atoms, we assign our five structures in a different states in ADO catalytic reaction below.

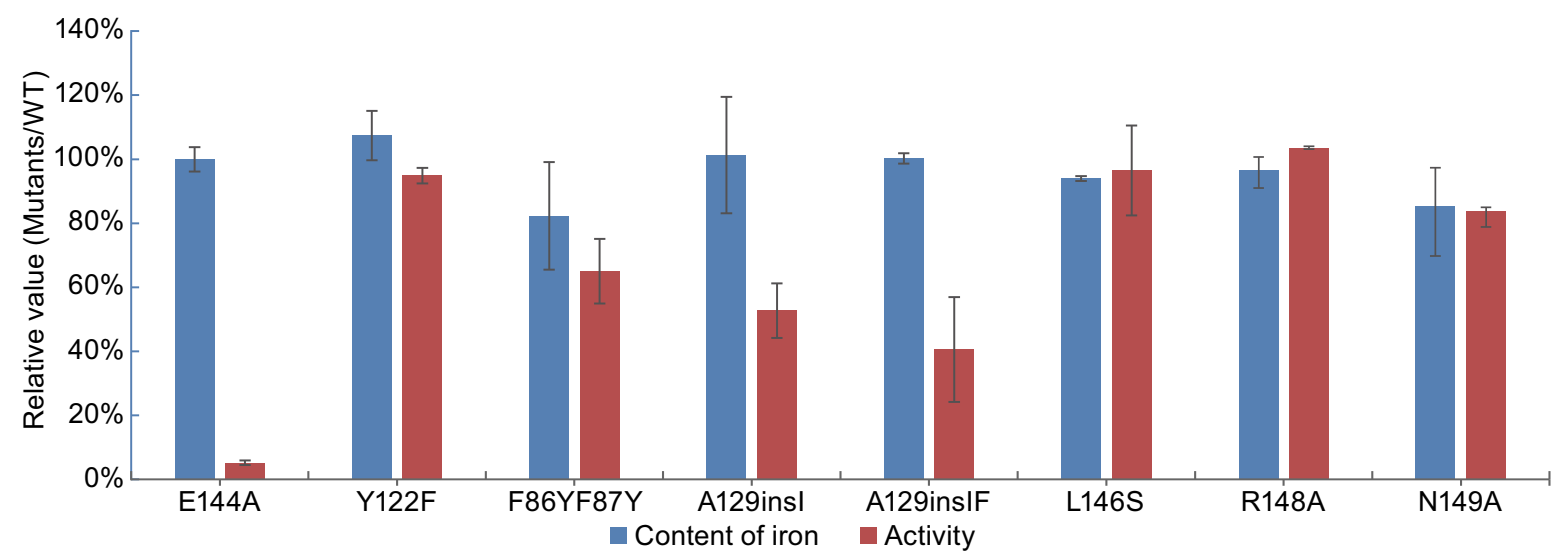

Figure 4. Enzymatic activity and iron-binding capacity of cADO mutants relative to those of wild type proteins.
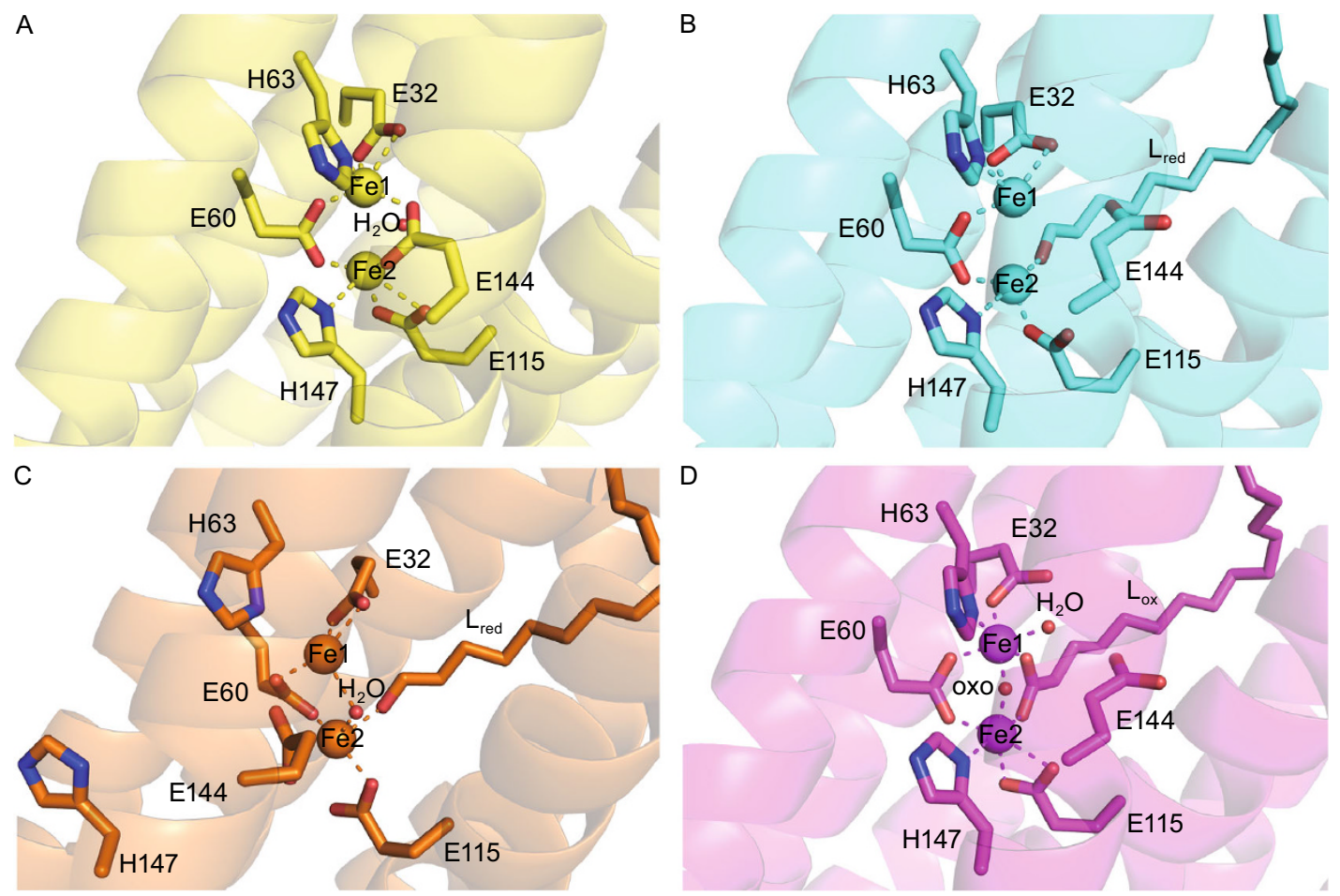

Figure 5. The coordination of di-iron center in the structures of Y122F (A), WT1 (B), F86YF87Y (C), and WT-HP (D). Iron atoms are shown in spheres, the coordinating residues and ligand are shown in sticks. The structures of Y122F, WT1, F86YF87Y, and WT-HP are shown in yellow, cyan, orange, and magenta, respectively. 
The substrate-free structure of $\mathrm{Y} 122 \mathrm{~F}$ represents the initial state of the reaction

In the Y122F structure, very little electron density was observed in the substrate channel, which is in contrast to all other four structures. However, there is still a little electron density remaining in the vicinity of the di-iron site, which we assigned to a water molecule forming a hydrogen-bond interactions with the carboxylic oxygen atoms of Glu144 and Glu115. This water molecule is not coordinated to either iron ions, with a distance of $3.28 \AA$ and $3.15 \AA$, respectively. Apart from harboring the vacant substrate channel, the Y122F mutant shows comparable enzymatic activity with wild type. This result is consistent with that of the equivalent Y135F mutant in PmADO (Schirmer et al., 2010). In the Y122F structure, the di-iron site is surrounded by the fourhelix bundle, each iron ion is penta-coordinated by two bridging carboxylates ligands (Glu60 and Glu144), one bidentate carboxylates and one histidine ligand (Glu32 and His63 for Fe1, Glu115 and His147 for Fe2) (Fig. 5A and Table 3). The coordination geometry of the two iron atoms is similar to that of other di-iron proteins in their rest state of

Table 3. Coordinating ligands and distances of two iron atoms in SeADO structures

\begin{tabular}{|c|c|c|c|c|}
\hline & $\begin{array}{l}\text { Y122F } \\
\text { (A) }\end{array}$ & $\begin{array}{l}\text { WT1 } \\
\text { (A) }\end{array}$ & $\begin{array}{l}\text { F86YF87Y } \\
\text { (B) }\end{array}$ & $\begin{array}{l}\text { WT-HP } \\
(A)^{*}\end{array}$ \\
\hline \multicolumn{5}{|l|}{$\mathrm{Fe} 1$} \\
\hline E32 (OE1) & 2.07 & 2 & 2.25 & 2.05 \\
\hline E32 (OE2) & 2.29 & 2.44 & 2.22 & \\
\hline H63 & 2.38 & 2.35 & & 2.25 \\
\hline E60 (OE1) & 1.91 & 1.99 & 2.17 & 2.0 \\
\hline E144 (OE2) & 2.10 & - & & - \\
\hline $\begin{array}{l}\text { Water2 } \\
\text { (only in } \\
\text { F86YF87Y) }\end{array}$ & & - & 2.46 & \\
\hline Water1 & & - & & 1.94 \\
\hline OXO & & - & & 1.81 \\
\hline LIGAND & & - & & 2.08 \\
\hline \multicolumn{5}{|l|}{$\mathrm{Fe} 2$} \\
\hline E115 (OE1) & 2.33 & & & 2.38 \\
\hline E115 (OE2) & 2.43 & 2.05 & 2.11 & 2.14 \\
\hline $\mathrm{H} 147$ & 2.13 & 2.3 & & 2.25 \\
\hline E60 (OE2) & 2.13 & 2.06 & 1.73 & 2.04 \\
\hline E144 (OE1) & 1.91 & - & & - \\
\hline $\begin{array}{l}\text { Water2 } \\
\text { (only in } \\
\text { F86YF87Y) }\end{array}$ & & & 2.2 & \\
\hline OXO & & - & & 1.92 \\
\hline Ligand & & 2.29 & 2.16 & 2.31 \\
\hline
\end{tabular}

* Molecule A of Y122F, WT1 and WT-HP structures, and molecule B of F86YF87Y structure were used to measure the distances. reduced forms (Du Bois et al., 2000; Eriksson et al., 1998; Hogbom et al., 2002; Lindqvist et al., 1996; Logan et al., 1998; Logan et al., 1996; Strand et al., 2004; Yang et al., 2000) which is consistent with the initial state of cADO in the reaction cycle. We assumed that this structure with a vacant substrate channel represents the initial and substrate-free status during the reaction cycle.

\section{The WT1 structure represents the state of ADO bound with substrate}

In the WT1 structure, a $L_{\text {red }}$ ligand, which was proposed to mimic the substrate aldehyde, was modeled in the substrate channel according to the electron density (Fig. 2B). The ligand approaches the di-iron cluster from the opposite side of His147, with its head-group binding directly to the $\mathrm{Fe} 2$ atom. This coordination mode suggests that $\mathrm{Fe} 2$ is the preferred iron for substrate binding. The water molecule, located near the di-iron site in the Y122F structure, is displaced by the head group of the $L_{\text {red }}$ ligand. The residue Glu144, which is located in helix $\mathrm{H} 5$, changes its rotamer and is not coordinated with either iron atoms. In addition, E115 alters its mode of $\mathrm{Fe} 2$ coordination, from bidentate to monodentate, while other four iron-coordinating residues stay unchanged, resulting in a distorted tetrahedral coordination of both $\mathrm{Fe} 1$ and Fe2 (Fig. 5B and Table 3). The structure of WT1 is likely to represent the state where the enzyme is bound with substrate. The structural comparison between WT1 and Y122F implied that the swing of Glu144 might be induced by ligand binding, thus enabled us to visualize the conformational change coupled with substrate binding in cADO active site for the first time.

\section{The F86YF87Y structure represents the state of $A D O$ where the oxygen path is formed}

In the molecule B of F86YF87Y structure, a segment (from residue 144-150) in helix $\mathrm{H} 5$ changes its conformation from helix to loop, which might be induced by the swing of Glu144 observed in WT1 structure. As a consequence, His147 moves away from the active site with a $9 \AA$ distance to Fe2. In addition, $\mathrm{H} 63$ is located more distantly from the active site, and the ligand bond between Fe1 atom and $\mathrm{H} 63$ is broken. The iron ions at the active site are bridged by the residue Glu60 together with a water molecule. However, the water molecule is in a different location from the one observed in the $\mathrm{Y} 122 \mathrm{~F}$ structure. The two iron atoms are maintaining their tetrahedral coordinations (Fig. 5C and Table 3). The relatively low coordination number in this structure indicates that the active site is in a reduced state, and should be highly sensitive to dioxygen (Nordlund and Eklund, 1995). In addition, a hole is formed at the protein surface as a result of helix $\mathrm{H} 5$ distortion, which exposes the di-iron cluster and the bridging water molecule to solvent (Fig. 6A and 6B). We assumed that the hole formed in the F86YF87Y structure serves as the access channel for the co-substrate dioxygen. 
Recent research revealed that the substrate-free ADO is relatively unreactive towards $\mathrm{O}_{2}$, and its $\mathrm{O}_{2}$ reactivity is triggered by substrate binding, which is referred to as a "substrate triggering" mechanism (Pandelia et al., 2013). Based on our structural analysis, we proposed that the substrate triggering is due to the conformational changes of Glu144 and helix $\mathrm{H} 5$ induced by substrate binding to create a path for $\mathrm{O}_{2}$. Therefore, we presumed that this structure represents the transient state at which ADO is awaiting the arrival of the co-substrate dioxygen.

\section{The WT-HP structure represents an intermediate state of $A D O$ where oxygen reacts with the substrate}

To explore the effects of $\mathrm{H}_{2} \mathrm{O}_{2}$ on ADO activity, a crystal of wild type SeADO was soaked in $\mathrm{H}_{2} \mathrm{O}_{2}$, and its structure (WT$\mathrm{HP}$ ) was solved. No electron density was visible for the $\mathrm{H}_{2} \mathrm{O}_{2}$, probably due to its unstable nature. $A L_{o x}$ ligand closely resembling a fatty acid molecule was built according to the electron density observed within this structure (Fig. 2A), which is nearly identical to the previously solved structure of PmADO (PDB code 2OC5). In the WT-HP structure, the helix
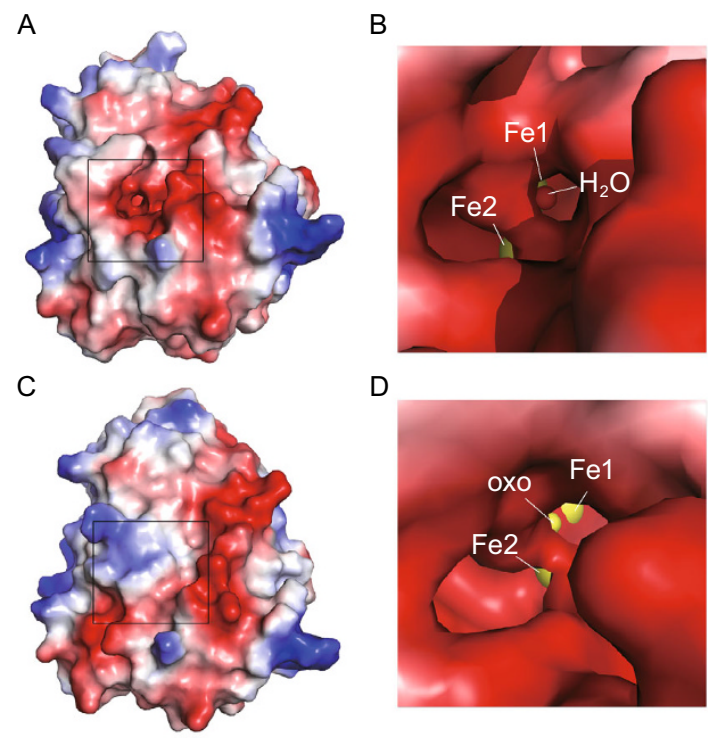

Figure 6. Electrostatic surface interpretation of SeADO structures. (A) Surface representation of F86YF87Y structure showed that a hole was formed in its surface due to the conformational change of helix H5. (B) The partial enlarged detail of surface interpretation of F86YF87Y structure, two iron atoms (shown as yellow spheres) and the water molecule (shown as red sphere) in the active center can be observed from the hole. (C) Surface representation of WT-HP structure. (D) The partial enlarged detail of surface representation of F86YF87Y structure with the di-iron cluster of WT-HP structure superimposed. The oxo bridge and the two iron atoms (shown as yellow spheres), which are hidden inside the ADO molecule in WT-HP structure (C), are accessible in F86YF87Y structure (D). conformation of $\mathrm{H} 5$ was restored, and the two coordinating residues His63 and His147 approach the active site and ligate the $\mathrm{Fe} 1$ and $\mathrm{Fe} 2$ atoms, respectively. The water molecule that bridges the two iron atoms in the F86YF87Y structure moves towards $\mathrm{Fe} 1$ and is not coordinated with $\mathrm{Fe} 2$ in the WT-HP structure. The two iron ions are bridged by one carboxylate ligand $\mathrm{E} 60$, the $\mathrm{L}_{\mathrm{ox}}$ ligand and an oxo group. Both iron atoms show saturated coordination with an octahedral geometry (Fig. 5D and Table 3). The higher coordination numbers of di-iron center, together with the fact that the crystal was obtained after being treated with strong oxidizer $\mathrm{H}_{2} \mathrm{O}_{2}$, lead to the speculation that the WT-HP structure represents an oxidized form of ADO. Furthermore, the coordination mode of two iron atoms in WT-HP structure shows a similar pattern to that observed for the R2 protein of ribonucleotide reductase (RNR-R2), in which the oxo bridge and the coordinated water exist at the di-iron site in the oxidized structure, while both are absent in the reduced structure (Logan et al., 1996). The superimposition of the F86YF87Y and WT-HP structures revealed that the hole at the protein surface, which is caused by the distortion of helix $\mathrm{H} 5$, exposes the di-iron sites and the oxo bridge (Fig. 6C and $6 \mathrm{D})$. This observation supports our hypothesis that the identified hole serves as dioxygen channel. We proposed that the $L_{\text {ox }}$ ligand is likely to be the analog of the possible intermediate product hemiacetal, thus the WT-HP structure may represent the intermediate state in reaction of cADO, following the entering of dioxygen and its reaction with the substrate.

\section{The WTO structure represents the inactive state of ADO}

The WTO structure is characterized by losing the di-iron cluster and by exhibiting a distorted conformation of helix $\mathrm{H} 5$. This structure is likely to represent the inactive state of SeADO, as it has lost its cofactor iron. We assume that if the loop conformation of helix $\mathrm{H} 5$, as revealed in the F86YF87Y structure, was not restored into a helical structure at the appropriate time, the solvent-accessible di-iron center may become unstable. Whereas the instability of the di-iron cluster further promotes the loop conformation, and thus results in a complete loss of the di-iron cluster, as shown in the WT0 structure (Fig. 1D and 1E). The structural flexibility of SeADO provides an explanation for its low iron occupancy, and may be in part responsible for the low enzymatic activity observed for cADO. To the best of our knowledge, the observation that the conformational change of one specific helix towards the loop correlates with the loss of the diiron cluster is the first case described for this superfamily.

\section{The proposed process of the catalytic reaction by cADO}

Among all the iron-coordinating residues, Glu144 remarkably alters its conformation among structures. A similar case was observed in other members of the di-iron protein family, such as RNR-R2 and the hydroxylase component of soluble 


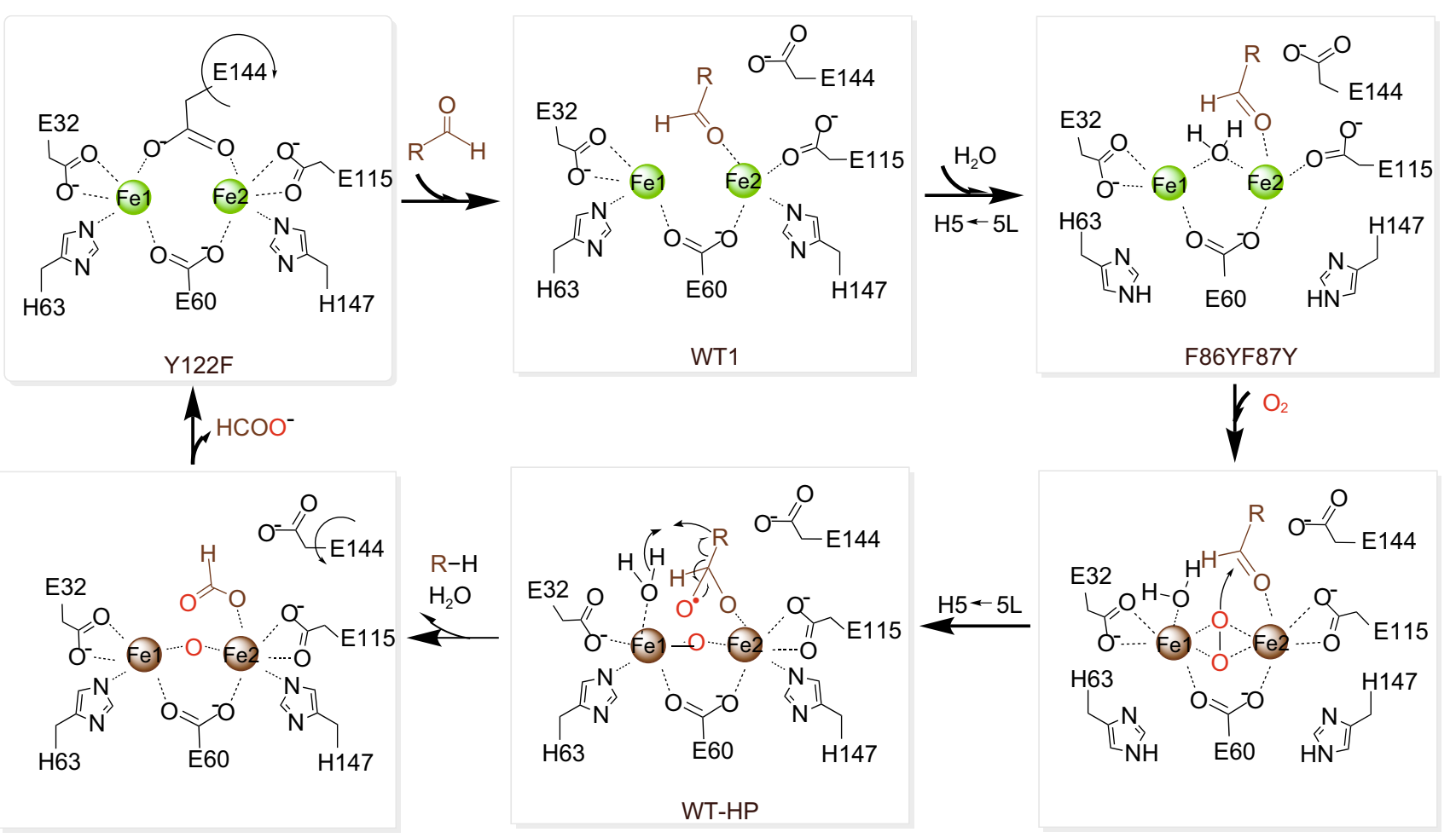

Figure 7. Proposed catalytic process of cADO based on the structures presented in this work.

methane monooxygenase. Both possess an essential ironcoordinating glutamic acid, which exhibits distinct conformations during their respective reactions (Kolberg et al., 2004; Sazinsky and Lippard, 2006; Whittington and Lippard, 2001). Apart from the structural information, our biochemical analysis showed that the E144A mutant has only $5 \%$ activity remaining, with similar iron content as measured for the wild type (Fig. 4 and Table 2). We therefore suggest that Glu144 plays an important role in catalysis.

Based on our structural and biochemical analysis, together with the previous report on ADO (Li et al., 2012; Li et al., 2011; Pandelia et al., 2013; Paul et al., 2013; Warui et al., 2011), we proposed a potential process of catalytic reaction for CADO (Fig. 7). Initially, the substrate ligates to the Fe2 and induces the swing of Glu144 away from the di-iron site and the conformational change of helix H5. The swing of Glu144 is essential for both inducing the distortion of $\mathrm{H} 5$ that facilitates the formation of the $\mathrm{O}_{2}$-entering path, and makes room for subsequent dioxygen coordination. Following the entering of $\mathrm{O}_{2}$ into the active site, the helical conformation of $\mathrm{H} 5$ is restored. Meanwhile, one oxygen atom forms the oxo bridge that ligates both iron atoms, and the other oxygen atom attacks the substrate aldehyde to form the intermediate product of hemiacetal. Then the scission of its $\mathrm{C} 1-\mathrm{C} 2$ bond occurs, with the bond likely to be under the attack of the Fe1-coordinating water, and this attack results in the release of the product alkane. Finally, Glu144 shifts back to the active site, bridging two iron atoms. The oxo-bridge is broken, and the product formate is released, together with one water molecule.
In summary, we determined five crystal structures of SeADO and revealed novel structural features around their active site. Snapshots of these consecutive states allow us to visualize the morphing of the active site during the reaction. Analysis of our structural and biochemical data highlights a number of important structural features that can influence the catalytic process and activity of cADO, including the conformational switch of the central part of helix $\mathrm{H} 5$, and the flexibility of residue Glu144. Together, these results provide new structural insights into the catalytic mechanism and allow us to propose a possible catalytic process of CADO, thus provides crucial information required for developing new strategies to improve its enzymatic activity, with the ultimate goal of producing fuel-grade alk(a/e)nes in a renewable and sustainable manner.

\section{MATERIALS AND METHODS}

Protein expression and purification

The codon-optimized gene encoding cADO from Synechococcus elongates PCC7942 was synthetized and cloned into the expression vector pET-28a(+) (Novagen). The constructs for mutant of SeADO were generated using the QuikChange sitedirected mutagenesis kit (Stratagene). The constructs were confirmed by DNA sequencing and transformed into $E$. coli BL21 (DE3). Protein expression was induced by adding isopropyl $\beta$-Dthiogalactoside (IPTG) to a final concentration of $1 \mathrm{mmol} / \mathrm{L}$. After being shaken at $37^{\circ} \mathrm{C}$ for approximately additional $4 \mathrm{~h}$, cultures were harvested by centrifugation at $6000 \times g$ at $4^{\circ} \mathrm{C}$ for $15 \mathrm{~min}$. To 
obtain the iron-bound cADO proteins, $2 \mathrm{mmol} / \mathrm{L}\left(\mathrm{NH}_{4}\right)_{2} \mathrm{SO}_{4} \mathrm{Fe}$ $\mathrm{SO}_{4} \cdot 6 \mathrm{H}_{2} \mathrm{O}$ was added in medium.

The cell pellet was homogenized in buffer containing $20 \mathrm{mmol} / \mathrm{L}$ Tris$\mathrm{HCl} \mathrm{pH} 7.8$ and $300 \mathrm{mmol} / \mathrm{L} \mathrm{NaCl}$ (buffer A), and sonicated. Cell debris was removed by centrifugation at $40,000 \times g$ for $30 \mathrm{~min}$. The supernatant was collected and loaded onto Ni-IDA resin (Chelating sepharose FF, GE Healthcare) and rinsed with buffer A $20 \mathrm{mmol} / \mathrm{L}$ imidazole. The protein was eluted from the affinity resin with buffer $A$ containing $250 \mathrm{mmol} / \mathrm{L}$ imidazole. The eluted fraction was concentrated and further purified by gel filtration on Superdex 75 (GE Healthcare) with elution buffer $50 \mathrm{mmol} / \mathrm{L}$ Hepes $\mathrm{pH} 7.2,150 \mathrm{mmol} / \mathrm{L} \mathrm{NaCl}$. The purified protein was concentrated to $10 \mathrm{mg} / \mathrm{mL}$ for crystallization.

Ferredoxin reductase and ferredoxin derived from Synechococcus elongates PCC7942 were constructed and purified as previously described (Zhang et al., 2013).

\section{Crystallization and $\mathrm{X}$-ray data collection}

Crystallization trials were carried out at $18^{\circ} \mathrm{C}$ by mixing equal volume of protein and reservoir solution using the sitting-drop vapor diffusion method. Crystals of WTO structure was harvested in condition of reservoir solution of $0.2 \mathrm{~mol} / \mathrm{L}$ Magnesium chloride hexahydrate, $0.1 \mathrm{~mol} / \mathrm{L}$ Tris hydrochloride $\mathrm{pH} 8.5,30 \%$ (w/v) PEG 4,000. To obtain the ironbound crystals, $4 \mathrm{mmol} / \mathrm{L}$ ferrous ammonium sulfate was added to SeADO protein solutions right before crystallization. The crystals of WT1 structure were harvested in reservoir solution containing $0.2 \mathrm{~mol} / \mathrm{L}$ L-proline, $0.1 \mathrm{~mol} / \mathrm{L}$ Hepes pH 7.1, 25\% (w/v) PEG1500. The crystals of Y122F and F86YF87Y were grown in the same solution with $0.02 \mathrm{~mol} / \mathrm{L}$ adenosine-5'-triphosphate disodium salt hydrate added. The crystal of WT1 was soaked in $10 \mathrm{mmol} / \mathrm{L} \mathrm{H}_{2} \mathrm{O}_{2}$ for 30 min before being flash frozen to obtain the crystal of WT-HP.

Crystals were flash-cooled in a nitrogen-gas stream at $100 \mathrm{~K}$ for data collection. Diffraction data of Y122F and F86YF87Y were collected on beamline BL17U at Shanghai Synchrotron Radiation Facility. Diffraction data of WT0 and WT1 were collected utilizing Rigaku RAXIS IV image plate detector at Institute of Biophysics (Chinese Academy of Sciences). Diffraction data of WT-HP were collected on BL17A at Photo Factory, Japan. Diffraction data were processed and scaled with HKL2000 package (Otwinowski and Minor, 1997).

\section{Structure determination and refinement}

The WTO model, which subsequently make a searching model for molecular replacement of other four structures, was solved by molecular replacement with Phaser_MR (Mccoy et al., 2007) using the PmADO structure (PDB code $2 \mathrm{OC}^{-}$) as a searching model. The model were rebuilded by AutoBuild in PHENIX package (Adams et al., 2010), following subjected to refinement by Phenix.refine (Adams et al., 2010) and COOT (Emsley et al., 2010). Figures of the structures were prepared by Pymol (DeLano Scientific, LLC). A summary of data collection and structure refinement statistics is given in Table 1.

Metal content determination and enzyme activity assay

The metal contents of the wild-type enzyme and mutants were determined by inductively coupled plasma optical emission spectrometer (ICP-OES), PerkinElmer 5300DV.
$\mathrm{N}$-heptanal was selected as the substrate to measure the activity of cADO proteins. Assays were performed in $1.5 \mathrm{~mL}$ gastight vials with a total volume of $500 \mu \mathrm{L}$, and reactions were conducted in $100 \mathrm{mmol} / \mathrm{L}$ HEPES buffer $\mathrm{pH} 7.2$ containing $100 \mathrm{mmol} / \mathrm{L} \mathrm{KCl}$ and $10 \%$ glycerol, with $15 \mu \mathrm{mol} / \mathrm{L}$ protein samples, $2 \mathrm{mmol} / \mathrm{L}$ of $\mathrm{n}$-heptanal in final $4 \%$ DMSO, $30 \mu \mathrm{g} / \mathrm{mL}$ ferredoxin, $0.04 \mathrm{U} / \mathrm{mL}$ ferredoxin reductase, $800 \mu \mathrm{mol} / \mathrm{L} \mathrm{NADPH}, 60 \mu \mathrm{mol} / \mathrm{L}$ ferrous ammonium sulphate. After being enrolled of all the components, reactions were shaken at $220 \mathrm{rpm}$ at $37^{\circ} \mathrm{C}$ for $30 \mathrm{~min}$. To determine the amount of $n$-hexane produced, a sample of the headspace was collected using a gastight sample lock Hamilton syringe and analysed by Shimadzu GC-2010 with DB-5 column. The amount of $n$-hexane produced was quantified by a standard curve of known concentrations of $n$-hexane.

For GC analysis the flow rate of the nitrogen carrier gas was $1.1 \mathrm{~mL} / \mathrm{min}$ and the inlet temperature was maintained at $220^{\circ} \mathrm{C}$. Injections were made in split mode with a split ratio of 2:1 and a total flow of $2 \mathrm{~mL} / \mathrm{min}$. The oven temperature was held at $40^{\circ} \mathrm{C}$ for $3 \mathrm{~min}$ and then increased to $120^{\circ} \mathrm{C}$ at $10^{\circ} \mathrm{C} / \mathrm{min}$, and finally maintained at $120^{\circ} \mathrm{C}$ for $2 \mathrm{~min}$. The FID detector was at $250^{\circ} \mathrm{C}$ with a continuous flow of $\mathrm{H} 2$ at $40 \mathrm{~mL} / \mathrm{min}$ and air at $400 \mathrm{~mL} / \mathrm{min}$. Chromatographic data were analyzed using the associated software.

\section{Determination of ligand(s) using GC-QqQ-MS/MS.}

$2 \mathrm{~g}$ of purified SeADO protein was acidified using $1 \mathrm{~mol} / \mathrm{L} \mathrm{HCl}$ to pH 3.0 and extracted with ethyl acetate. The organic layer was collected and dried by passing through $\mathrm{MgSO}_{4}$. The solvent was evaporated by rotary evaporator and nitrogen (N-EVAP) to $100 \mu \mathrm{L}$. The sample was trimethylsilylated for analysis using BSTFA + 1\% TMCS (Sigma). All spectra were recorded on an Agilent 7890A GC system connected to an Agilent $7000 \mathrm{~B}$ triple quadrupole MSD with electron impact ionization mode. A 1- $\mu \mathrm{L}$ portion of the derivatized extract was injected in splitless mode onto the column. The column used was a DB-5ms (30 m $\times 250 \mu \mathrm{m} \times 0.25 \mu \mathrm{m}$ film thickness, Agilent J\&W ScientiWc, USA) fused silica capillary column. Injector temperature was $280^{\circ} \mathrm{C}$ and the oven program was as follows: oven temperature was held at $60^{\circ} \mathrm{C}$ for $2 \mathrm{~min}$ and then increased to $240^{\circ} \mathrm{C}$ at $10^{\circ} \mathrm{C} / \mathrm{min}$ and then increased to $300^{\circ} \mathrm{C}$ at $20^{\circ} \mathrm{C} / \mathrm{min}$ finally maintained at $300^{\circ} \mathrm{C}$ for $5 \mathrm{~min}$. Helium was used as the carrier gas for $\mathrm{GC}$ at a flow rate of $1.0 \mathrm{~mL} / \mathrm{min}$, and the inlet temperature was maintained at $280^{\circ} \mathrm{C}$ with splitless. Chromatographic data were acquired and processed using MassHunter Workstation Quantitative Software.

\section{ACKNOWLEDGMENTS}

We would like to thank Yi Han and Shengquan Liu at the Institute of Biophysics, CAS and the staffs at Shanghai Synchrotron Radiation Facility and Photo Factory, Japan, respectively, for help during X-ray data collection. We also thank Wei Shao at Beijing Center for Physical and Chemical Analysis for help with the GC analysis, Zhen Xue at Institute of Botany, CAS for providing help for the GC-QqQMS/MS analysis, and Hongzhi Zhang at Institute of Geographic Sciences and Natural Resources Research, CAS for technical support with the metal content analysis by ICP-OES. This work was supported by the National Basic Research Program (973 Program) (Nos. 2011CBA00902 and 2011CBA00907), Strategic Priority Research Program of the Chinese Academy of Sciences (XDB08020302), National Natural Science Foundation of China 
(Grant Nos. 31021062 and 31170765), and CAS Cross and Cooperation Team for Scientific Innovation (Y31102110A).

\section{ABBREVIATIONS}

$A A R$, acyl-ACP reductase; $A D O$, aldehyde-deformylating oxygenase; CADO, ADO from cyanobacteria; Fd/FR/N, ferredoxin, ferredoxin reductase, and NADPH; ICP-OES, inductively coupled plasma optical emission spectrometer; IPTG, isopropyl $\beta$-D-thiogalactoside; P/N, phenazine methosulfate and NADH; Pm, Prochlorococcus marinus MIT9313; RNR-R2, the R2 protein of ribonucleotide reductase; Se, Synechococcus elongates PCC7942.

\section{COMPLIANCE WITH ETHICS GUIDELINES}

Chenjun Jia, Mei Li, Jianjun Li, Jingjing Zhang, Hongmei Zhang, Peng Cao, Xiaowei Pan, Xuefeng Lu, and Wenrui Chang declare that they have no conflict of interest.

This article does not contain any studies with human or animal subjects performed by the any of the authors.

\section{OPEN ACCESS}

This article is distributed under the terms of the Creative Commons Attribution License which permits any use, distribution, and reproduction in any medium, provided the original author(s) and the source are credited.

\section{REFERENCES}

Adams PD, Afonine PV, Bunkoczi G, Chen VB, Davis IW, Echols N, Headd JJ, Hung LW, Kapral GJ, Grosse-Kunstleve RW et al (2010) PHENIX: a comprehensive Python-based system for macromolecular structure solution. Acta Crystallogr D 66:213221

Andre C, Kim SW, Yu XH, Shanklin J (2013) Fusing catalase to an alkane-producing enzyme maintains enzymatic activity by converting the inhibitory byproduct $\mathrm{H}_{2} \mathrm{O}_{2}$ to the cosubstrate $\mathrm{O}_{2}$. Proc Natl Acad Sci USA 110:3191-3196

Aukema KG, Makris TM, Stoian SA, Richman JE, Munck E, Lipscomb JD, Wackett LP (2013) Cyanobacterial aldehyde deformylase oxygenation of aldehydes yields $n-1$ aldehydes and alcohols in addition to alkanes. ACS Catal 3:2228-2238

Das D, Eser BE, Han J, Sciore A, Marsh EN (2011) Oxygenindependent decarbonylation of aldehydes by cyanobacterial aldehyde decarbonylase: a new reaction of diiron enzymes. Angew Chem 50:7148-7152

Das D, Ellington B, Paul B, Marsh EN (2014) Mechanistic insights from reaction of alpha-oxiranyl-aldehydes with cyanobacterial aldehyde deformylating oxygenase. ACS Chem Biol 9:570-577

Du Bois J, Mizoguchi TJ, Lippard SJ (2000) Understanding the dioxygen reaction chemistry of diiron proteins through synthetic modeling studies. Coord Chem Rev 200:443-485

Emsley P, Lohkamp B, Scott WG, Cowtan K (2010) Features and development of Coot. Acta Crystallogr D 66:486-501

Eriksson M, Jordan A, Eklund H (1998) Structure of Salmonella typhimurium nrdF ribonucleotide reductase in its oxidized and reduced forms. Biochemistry 37:13359-13369
Eser BE, Das D, Han J, Jones PR, Marsh EN (2012) Correction to oxygen-independent alkane formation by non-heme iron-dependent cyanobacterial aldehyde decarbonylase: investigation of kinetics and requirement for an external electron donor. Biochemistry 51:5703

Hogbom M, Huque Y, Sjoberg BM, Nordlund P (2002) Crystal structure of the di-iron/radical protein of ribonucleotide reductase from corynebacterium ammoniagenes. Biochemistry 41:13811389

Khara B, Menon N, Levy C, Mansell D, Das D, Marsh EN, Leys D, Scrutton NS (2013) Production of propane and other short-chain alkanes by structure-based engineering of ligand specificity in aldehyde-deformylating oxygenase. ChemBioChem 14:12041208

Kolberg M, Strand KR, Graff P, Andersson KK (2004) Structure, function, and mechanism of ribonucleotide reductases. Biochim Biophys Acta 1699:1-34

Krebs C, Bollinger JM, Booker SJ (2011) Cyanobacterial alkane biosynthesis further expands the catalytic repertoire of the ferritinlike 'di-iron-carboxylate' proteins. Curr Opin Chem Biol 15:291303

Kurtz DM (1997) Structural similarity and functional diversity in diiron-oxo proteins. J Biol Inorg Chem 2:159-167

Li N, Norgaard H, Warui DM, Booker SJ, Krebs C, Bollinger JM Jr (2011) Conversion of fatty aldehydes to alka(e)nes and formate by a cyanobacterial aldehyde decarbonylase: cryptic redox by an unusual dimetal oxygenase. J Am Chem Soc 133:6158-6161

Li N, Chang WC, Warui DM, Booker SJ, Krebs C, Bollinger JM Jr (2012) Evidence for only oxygenative cleavage of aldehydes to alk(a/e)nes and formate by cyanobacterial aldehyde decarbonylases. Biochemistry 51:7908-7916

Lindqvist Y, Huang W, Schneider G, Shanklin J (1996) Crystal structure of delta9 stearoyl-acyl carrier protein desaturase from castor seed and its relationship to other di-iron proteins. EMBO J 15:4081-4092

Logan DT, Su XD, Aberg A, Regnstrom K, Hajdu J, Eklund H, Nordlund P (1996) Crystal structure of reduced protein R2 of ribonucleotide reductase: the structural basis for oxygen activation at a dinuclear iron site. Structure 4:1053-1064

Logan DT, deMare F, Persson BO, Slaby A, Sjoberg BM, Nordlund P (1998) Crystal structures of two self-hydroxylating ribonucleotide reductase protein $\mathrm{R} 2$ mutants: structural basis for the oxygeninsertion step of hydroxylation reactions catalyzed by diiron proteins. Biochemistry 37:10798-10807

Mccoy AJ, Grosse-Kunstleve RW, Adams PD, Winn MD, Storoni LC, Read RJ (2007) Phaser crystallographic software. J Appl Crystallogr 40:658-674

Merkx M, Kopp DA, Sazinsky MH, Blazyk JL, Muller J, Lippard SJ (2001) Dioxygen activation and methane hydroxylation by soluble methane monooxygenase: a tale of two irons and three proteins. Angew Chem Int Ed 40:2782-2807

Nordlund P, Eklund H (1995) Di-iron-carboxylate proteins. Curr Opin Struct Biol 5:758-766

Otwinowski Z, Minor W (1997) Processing of X-ray diffraction data collected in oscillation mode. Methods Enzymol 276:307-326

Pandelia ME, Li N, Norgaard H, Warui DM, Rajakovich LJ, Chang WC, Booker SJ, Krebs C, Bollinger JM (2013) Substrate- 
triggered addition of dioxygen to the diferrous cofactor of aldehyde-deformylating oxygenase to form a diferric-peroxide intermediate. J Am Chem Soc 135(42):15801-15812

Paul B, Das D, Ellington B, Marsh EN (2013) Probing the mechanism of cyanobacterial aldehyde decarbonylase using a cyclopropyl aldehyde. J Am Chem Soc 135:5234-5237

Sazinsky MH, Lippard SJ (2006) Correlating structure with function in bacterial multicomponent monooxygenases and related diiron proteins. Acc Chem Res 39:558-566

Schirmer A, Rude MA, Li X, Popova E, del Cardayre SB (2010) Microbial biosynthesis of alkanes. Science 329:559-562

Strand KR, Karlsen S, Kolberg M, Rohr AK, Gorbitz CH, Andersson KK (2004) Crystal structural studies of changes in the native dinuclear iron center of ribonucleotide reductase protein R2 from mouse. J Biol Chem 279:46794-46801

Wang W, Liu X, Lu X (2013) Engineering cyanobacteria to improve photosynthetic production of alka(e)nes. Biotechnol Biofuels 6:69

Wang Q, Huang X, Zhang J, Lu X, Li S, Li JJ (2014) Engineering self-sufficient aldehyde deformylating oxygenases fused to alternative electron transfer systems for efficient conversion of aldehydes into alkanes. Chem Commun 50:4299-4301
Warui DM, Li N, Norgaard H, Krebs C, Bollinger JM Jr, Booker SJ (2011) Detection of formate, rather than carbon monoxide, as the stoichiometric coproduct in conversion of fatty aldehydes to alkanes by a cyanobacterial aldehyde decarbonylase. J Am Chem Soc 133:3316-3319

Whittington DA, Lippard SJ (2001) Crystal structures of the soluble methane monooxygenase hydroxylase from methylococcus capsulatus (Bath) demonstrating geometrical variability at the dinuclear iron active site. J Am Chem Soc 123:827-838

Yang YS, Baldwin J, Ley BA, Bollinger JM, Solomon EI (2000) Spectroscopic and electronic structure description of the reduced binuclear non-heme iron active site in ribonucleotide reductase from E. coli: comparison to reduced delta(9) desaturase and electronic structure contributions to differences in $0-2$ reactivity. J Am Chem Soc 122:8495-8510

Zhang J, Lu X, Li JJ (2013) Conversion of fatty aldehydes into alk (a/e)nes by in vitro reconstituted cyanobacterial aldehyde-deformylating oxygenase with the cognate electron transfer system. Biotechnol Biofuels 6:86 